\title{
Effect of Mass Drug Administration with a Single Dose of Albendazole on Ascaris lumbricoides and Trichuris trichiura Infection among Schoolchildren in Yangon Region, Myanmar
}

\author{
Jong-Yil Chai ${ }^{1,2, *, \dagger}$, Woon-Mok Sohn ${ }^{3, \dagger}$, Sung-Jong Hong ${ }^{4}$, Bong-Kwang Jung ${ }^{1}$, Sooji Hong', Seon Cho', Jong-Bok Park', \\ In-Sung Kim¹, Sunkyoung Kim¹, Keon-Hoon Lee', Hoo-Gn Jeoung', Thi Thi Htoon ${ }^{5}$, Htay Htay Tin ${ }^{5}$

\begin{abstract}
1'Institute of Parasitic Diseases, Korea Association of Health Promotion, Seoul 07649, Korea; '2Department of Tropical Medicine and Parasitology, Seoul National University College of Medicine, Seoul 03080, Korea; ${ }^{3}$ Department of Parasitology and Tropical Medicine, and Institute of Health Sciences, Gyeongsang National University School of Medicine, Jinju 52727, Korea; ${ }^{4}$ Department of Environmental Medical Biology, Chung-Ang University College of Medicine, Seoul 06974, Korea; ${ }^{5}$ National Health Laboratory, Yangon 11191, Myanmar
\end{abstract}

\begin{abstract}
Soil-transmitted helminths, including Ascaris lumbricoides and Trichuris trichiura, are important intestinal parasites mostly affecting younger people in developing countries. In 2014-2015, we performed mass fecal examinations targeting a total of 2,227 schoolchildren in 3 districts (South Dagon, North Dagon, and Hlaing-thar-yar) of Yangon Region, Myanmar, using the Kato-Katz thick smear technique. The egg positive children were subjected to a mass drug administration (MDA) using a single oral dose of $400 \mathrm{mg}$ albendazole. The pre-treatment egg positive rate (EPG/person) of $A$. lumbricoides averaged $17.2 \%$ (15,532); it was $25.2 \%(21,796), 14.2 \%(11,816)$, and $12.8 \%(12,983)$ in 3 districts, respectively, and that of T. trichiura averaged $19.4 \%(1,074)$, and was $24.1 \%(1,040), 12.3 \%(852)$, and $21.2 \%(1,330)$ in 3 districts, respectively. Follow-up fecal examinations performed 4 months post-MDA revealed considerable decreases of $A$. lumbricoides prevalence (EPG/person) to av. 8.3\% (12,429), and 13.7\% (17,640), 8.0\% (7,797), and 4.5\% (11,849) in 3 districts, respectively. However, T. trichiura did not show any recognizable decrease in the prevalence (EPG/person) remaining at av. 18.2\% (862), and 18.5\% (888), 11.5\% (812), and 23.3\% (887) in 3 districts, respectively. The results demonstrated difficulty in short-term control of $T$. trichiura by MDA using albendazole and suggested necessity of either a long-term MDA (>10 years) or changing the albendazole regimen into 2 3-day course (total 800 or 1,200 mg), or using an alternative drug/drug combination.
\end{abstract}

Key words: Ascaris lumbricoides, Trichuris trichiura, prevalence, effect of control, albendazole, schoolchildren, Myanmar

Soil-transmitted helminths (STHs), including Ascaris lumbricoides, hookworms, and Trichuris trichiura, are the most common intestinal parasites affecting more than 1.5 billion people worldwide [1]. These infections affect especially children in developing countries and are associated with poor growth, reduced physical activity, and impaired learning ability [2]. In Myanmar, the prevalence of A. lumbricoides and T. trichiura among schoolchildren has been high, whereas that of hookworms has been comparatively low [2-4].

Repeated mass fecal examinations followed by mass drug

- Received 22 January 2020, revised 21 February 2020, accepted 21 February 2020.

*Corresponding author (cjy@snu.ac.kr)

${ }^{\dagger}$ These authors contributed equally to this work.

(c) 2020, Korean Society for Parasitology and Tropical Medicine

This is an Open Access article distributed under the terms of the Creative Commons Attribution Non-Commercial License (https://creativecommons.org/licenses/by-nc/4.0) which permits unrestricted non-commercial use, distribution, and reproduction in any

medium, provided the original work is properly cited. administration (MDA), environmental sanitation including remodeling of latrines and prohibition of night soil fertilizers, and health education for improving personal hygiene are the 3 basic control strategies for STH infections [5]. Among these, MDA using a proper anthelmintic drug is the most feasible and efficient method. Anthelmintics most popularly used for STH control are albendazole and mebendazole [1]; the recommended regimen of albendazole is $400 \mathrm{mg}$ given in a single dose $[4,6]$, and that of mebendazole is $100 \mathrm{mg}$ in a single dose [6]. However, the sensitivity of each helminth species to MDA and anthelmintic drugs varies depending on the species (A. lumbricoides, hookworms, or T. trichiura) and might also be associated with drug resistance of helminths [1].

The Korea Association of Health Promotion (KAHP), Seoul, Korea undertook an international health promotion project entitled, "Korea-Myanmar Health Promotion Project for Ele- 


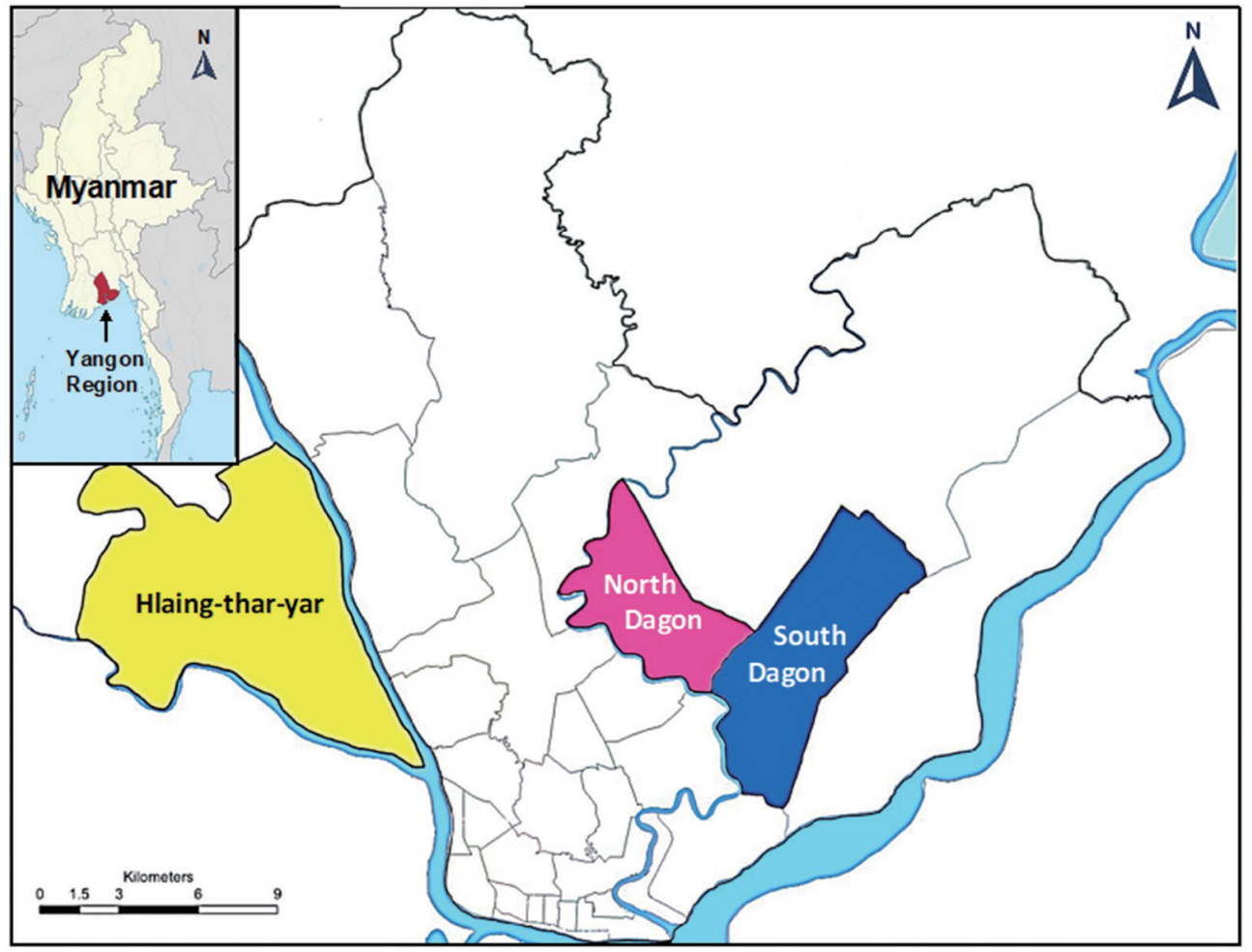

Fig. 1. Map showing the surveyed areas in Yangon Region, Myanmar. Schoolchildren of 20 primary schools in 3 districts (South Dagon, North Dagon, and Hlaing-thar-yar) were subjected for this study.

mentary Schoolchildren of the Vulnerable Areas around Yangon, Myanmar". The main purpose of the project was intestinal parasite control among schoolchildren under the agreement between 2 countries (as of 16 June 2013; IRB was not available at the time of this survey). In 2014-2015, we performed mass fecal examinations targeting schoolchildren in 20 Basic Education Primary Schools (BEPS) located in 3 districts (South Dagon, North Dagon, and Hlaing-thar-yar) of Yangon Region. MDA was performed on egg positive children using a single oral dose of albendazole. Follow-up fecal examinations were done 4 months later. The short-term (4-month) control efficacy in response to MDA appeared to be quite different between A. lumbricoides (high efficacy) and T. trichiura (poor efficacy). The purpose of this paper is to present the results of MDA with analyses of the factors related to the effect of control.

The 20 BEPS consisted of 6 schools in South Dagon, 6 schools in North Dagon, and 8 schools in Hlaing-thar-yar district (Fig. 1). Fecal examinations were performed on a total of 2,227 schoolchildren (aged 6-8 years, including almost the same numbers of boys and girls) using the Kato-Katz thick smear technique (1 smear per child). The results revealed that the egg positive rate of any kinds of helminths averaged 30.9\%; the rate being $40.4 \%$ (33.3-52.0\% by school) in South Dagon, 21.9\% (8.1-54.2\%) in North Dagon, and 30.2\% (23.0$38.7 \%$ ) in Hlaing-thar-yar (Table 1). The egg positive rate (EPG/person) of A. lumbricoides averaged $17.2 \%(15,532)$, and by district $25.2 \%(21,796), 14.2 \%(11,816)$, and $12.8 \%$ $(12,983)$, respectively, and that of T. trichiura averaged $19.4 \%$ $(1,074)$, and by district $24.1 \%(1,040), 12.3 \%$ (852), and $21.2 \%(1,330)$. The egg positive rate of hookworms was $0.2 \%$ on average, and by district $0.1 \%, 0.1 \%$, and $0.4 \%$, and that of Opisthorchis viverrini/minute intestinal flukes (MIF) averaged $0.1 \%$, and by district $0.1 \%, 0.0 \%$, and $0.1 \%$, in 3 districts, respectively (Table 1). The results were not significantly different $(P>0.05)$ between boys and girls (data not shown).

MDA was performed on a selective treatment manner, and a total of 688 helminth egg positive cases were given each a single oral dose of $400 \mathrm{mg}$ albendazole (Shinpoong Pharm Co., Seoul, Korea). Two trematode egg positive children were given additionally praziquantel $40 \mathrm{mg} / \mathrm{kg}$ in a single dose. The MDA coverage rate exceeded 95-98\% in each school but there were a 
Table 1. Prevalence of Ascaris lumbricoides, Trichuris trichiura, and other helminths among schoolchildren in 3 districts of Yangon area, Myanmar (2014-2015)

\begin{tabular}{|c|c|c|c|c|c|c|c|}
\hline \multirow[b]{2}{*}{ District/school code } & \multirow[b]{2}{*}{ No. exam. } & \multicolumn{6}{|c|}{ Egg positive rate (\%) } \\
\hline & & $\begin{array}{c}\text { Any } \\
\text { helminths }{ }^{a}\end{array}$ & $\begin{array}{c}\text { Ascaris } \\
\text { lumbricoides }\end{array}$ & $\begin{array}{l}\text { Trichuris } \\
\text { trichiura }\end{array}$ & $\begin{array}{l}\text { Hook- } \\
\text { worms }\end{array}$ & $\begin{array}{l}\text { Opisthorchis } \\
\text { viverrini/MIF }\end{array}$ & Others ${ }^{c}$ \\
\hline \multicolumn{8}{|l|}{ South Dagon } \\
\hline BEPS ${ }^{d}-A$ & 84 & 34.5 & 16.7 & 25.0 & 1.2 & 1.2 & 4.8 \\
\hline BEPS-B & 50 & 52.0 & 30.0 & 44.0 & 0 & 0 & 0 \\
\hline BEPS-C & 132 & 46.2 & 32.6 & 26.5 & 0 & 0 & 2.3 \\
\hline BEPS-D & 198 & 33.3 & 17.7 & 19.2 & 0 & 0 & 1.0 \\
\hline BEPS-E & 125 & 38.4 & 27.2 & 20.0 & 0 & 0 & 0.8 \\
\hline BEPS-F & 124 & 46.8 & 31.5 & 24.8 & 0 & 0 & 1.6 \\
\hline Subtotal & 713 & 40.4 & $25.2^{e}$ & 24.1 & 0.1 & 0.1 & 1.7 \\
\hline \multicolumn{8}{|l|}{ North Dagon } \\
\hline BEPS-G & 79 & 12.7 & 6.3 & 6.3 & 0 & 0 & 1.3 \\
\hline BEPS-H & 131 & 54.2 & 45.0 & 26.7 & 0 & 0 & 2.3 \\
\hline BEPS-I & 135 & 8.1 & 3.0 & 6.7 & 0 & 0 & 0.7 \\
\hline BEPS-J & 169 & 8.3 & 3.0 & 5.3 & 0 & 0 & 0.6 \\
\hline BEPS-K & 107 & 13.1 & 1.9 & 13.1 & 0 & 0 & 0 \\
\hline BEPS-L & 64 & 46.9 & 34.4 & 18.8 & 1.6 & 0 & 3.1 \\
\hline Subtotal & 685 & 21.9 & $14.2^{f}$ & 12.3 & 0.1 & 0 & 1.2 \\
\hline \multicolumn{8}{|l|}{ Hlaing-Thar-yar } \\
\hline BEPS-M & 163 & 23.0 & 11.7 & 15.3 & 0 & 0 & 2.5 \\
\hline BEPS-N & 79 & 25.3 & 10.1 & 21.5 & 0 & 0 & 0 \\
\hline BEPS-O & 96 & 24.0 & 8.3 & 18.8 & 0 & 0 & 0 \\
\hline BEPS-P & 141 & 33.3 & 11.3 & 21.3 & 0.7 & 0 & 4.3 \\
\hline BEPS-Q & 75 & 38.7 & 13.3 & 33.3 & 1.3 & 0 & 0 \\
\hline BEPS-R & 86 & 33.7 & 11.6 & 23.3 & 1.2 & 0 & 1.2 \\
\hline BEPS-S & 111 & 32.4 & 17.1 & 22.5 & 0 & 0.9 & 0.9 \\
\hline BEPS-T & 78 & 34.6 & 20.5 & 20.5 & 0 & 0 & 1.3 \\
\hline Subtotal & 829 & 30.2 & $12.8^{g}$ & 21.2 & 0.4 & 0.1 & 1.6 \\
\hline Total & 2,227 & 30.9 & $17.2^{h}$ & 19.4 & 0.2 & 0.1 & 1.5 \\
\hline
\end{tabular}

aHelminth egg positive rates were not significantly different between boys and girls $(P>0.05)$.

${ }^{b}$ Minute intestinal fluke.

'Others included eggs of Enterobius vermicularis and Trichostrongylus sp.

${ }^{\mathrm{d} B a s i c}$ Education Primary School.

eUnfertilized egg positive rate was $16.7 \%$ and fertilized egg positive rate was $16.0 \%$.

IUnfertilized egg positive rate was 8.5\% and fertilized egg positive rate was $8.5 \%$.

Unfertilized egg positive rate was $9.3 \%$ and fertilized egg positive rate was $6.8 \%$.

hunfertilized egg positive rate was $11.4 \%$ and fertilized egg positive rate was $10.2 \%$.

few children dropped-out from the MDA (data not shown). The significance of differences in the prevalence before and after the MDA were statistically evaluated using the student's $t$-test.

At 4 months after the MDA, follow-up fecal examinations (1 Kato-Katz smear for each child) were performed on the same schools, and the efficacy of the MDA for reduction of A. lumbricoides and $T$. trichiura prevalence and worm burden was assessed. Possible bias due to a few new attendees in each school was neglected. The efficacy of the MDA was evaluated to be fairly satisfactory for A. lumbricoides as the pre-treatment average egg positive rate of $17.2 \%$ was decreased to lower than half level, 8.3\% $(P<0.05)$ (Fig. 2), and the pre-treatment EPG/person of 15,532 decreased to 12,429 after the MDA $(P>0.05)$ (Fig. 3). This decreasing trend of A. lumbricoides was similar among 3 districts (Figs. 2, 3) and also recognizable among different schools, although some schools, like BEPS-A, B, I, and $\mathrm{Q}$, showed no significant decreases in the prevalence $(P>0.05)$ (data not shown).

However, the efficacy of the MDA against T. trichiura was far from satisfactory (Fig. 2). The average pre-treatment egg positive rate, 19.4\%, in 3 districts was not significantly decreased after the MDA which remained at $18.2 \%$ at follow-up examinations $(P>0.05)$ (Fig. 2), although the average EPG of infected schoolchildren was decreased a little, from 1,074 to 862 $(P>0.05)$ (Fig. 3). Insignificant and minor decreasing trends $(P>0.05)$ were seen in 2 districts, South Dagon and North Dagon (Figs. 2, 3), and a slight increase $(P>0.05)$ in the prevalence vs a remarkable decrease in $\mathrm{EPG} /$ person appeared in 

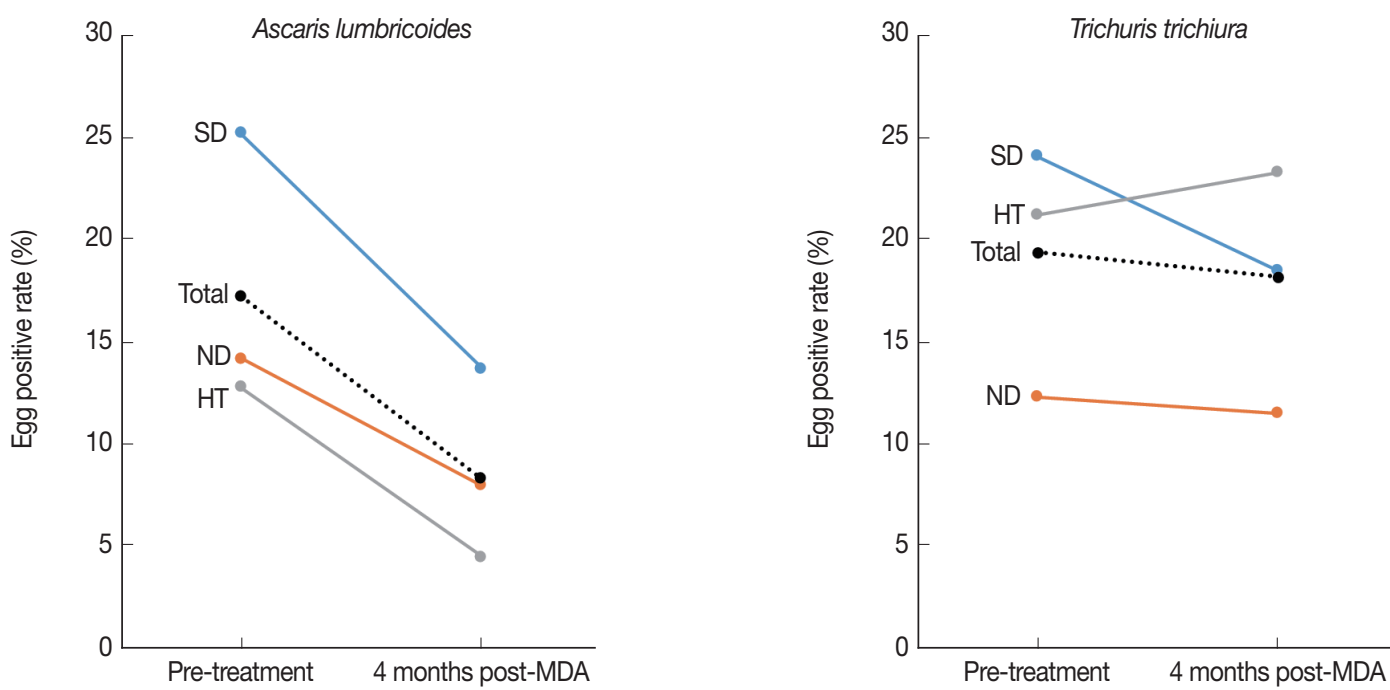

Fig. 2. Pre- and post-MDA prevalences of Ascaris lumbricoides and Trichuris trichiura among schoolchildren in 3 districts of Yangon Region, Myanmar. SD, South Dagon; ND, North Dagon; HT, Hlaing-thar-yar.
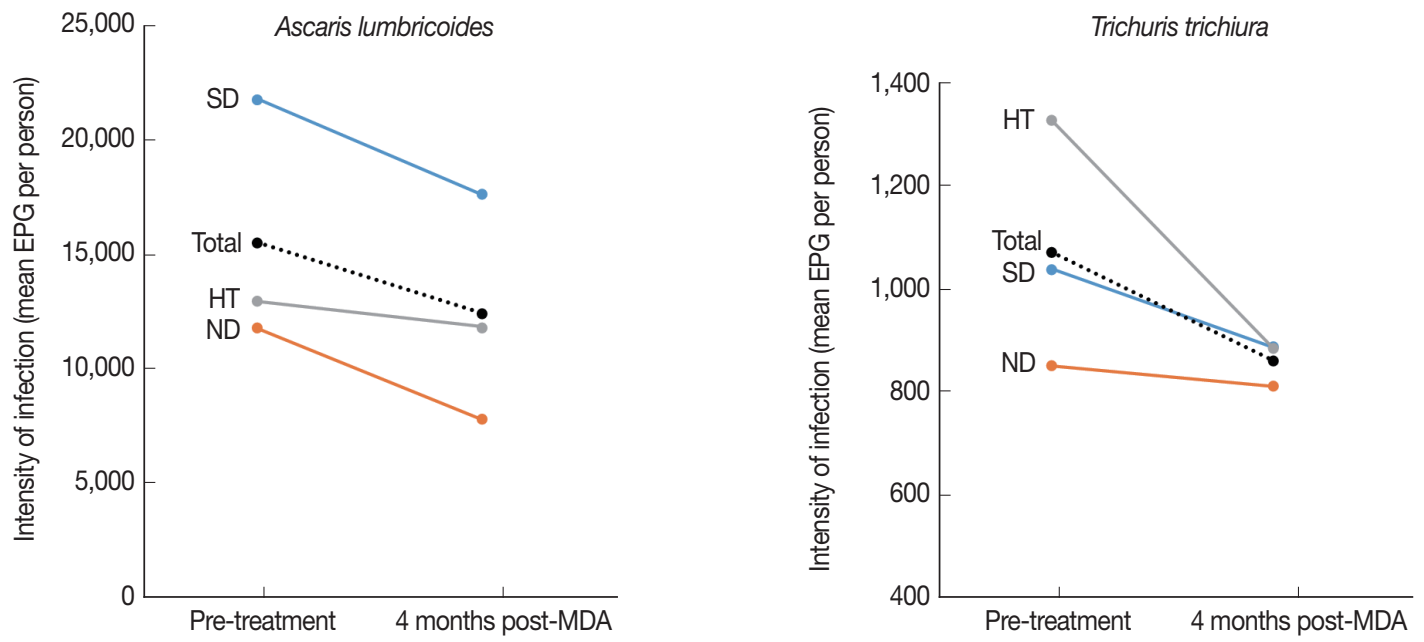

Fig. 3. Pre- and post-MDA intensity of infection (average EPG/person) of Ascaris lumbricoides and Trichuris trichiura among schoolchildren in 3 districts of Yangon Region, Myanmar. SD, South Dagon; ND, North Dagon; HT, Hlaing-thar-yar.

Hlaing-thar-yar district (Figs. 2, 3). The majority of individual schools revealed more or less decreasing trends, while some of them, including BEPS-H, O, Q, R, and T schools, showed slightly increasing trends in the prevalence of $T$. trichiura (data not shown).

The high sensitivity of A. lumbricoides to benzimidazoles (albendazole and mebendazole) has been well documented $[6,7]$. The cure rate of albendazole $(400 \mathrm{mg})$ for A. lumbricoides infection was reported to be $82-100 \%$ [6] or 93.2-97.3\% [7]. However, the sensitivity of T. trichiura to albendazole or mebendazole has been reported to be generally low and unsatisfactory $[1,6,7]$. The cure rate of $400 \mathrm{mg}$ single oral dose of albendazole for treating T. trichiura infection was reported to be $27-81 \%$ [6] or less, $21.0-42.5 \%$ [7].

Our study demonstrated that the efficacy of MDA using a single dose of albendazole was fairly good for reduction of the prevalence and intensity of infection of A. lumbricoides (from $17.2 \%$ to $8.3 \%$ in average egg positive rate and from 15,532 to 12,429 in EPG/person) at 4 months post-MDA. A large portion of $8.3 \%$ in prevalence at follow-up was regarded to be due to reinfection during 4 months after the MDA. However, its efficacy was far from satisfactory for short-term control of $T$. trichiura. The average prevalence before the MDA was 19.4\% but it remained to be still high after 4 months, 18.2\%. The egg 
reduction was fairly remarkable in Hlaing-thar-yar district but less remarkable in 2 other districts. The failure in reduction of T. trichiura prevalence could be due to 2 basic factors; one is limitation of the drug efficacy, and the other is rapid reinfection after the MDA. However, the importance of reinfection may not be so great considering the biology and life cycle of $T$. trichiura. The pre-patent period of T. trichiura was estimated to be 101-114 days in a human volunteer after an experimental intake of eggs [10]. It is thus unlikely that $T$. trichiura worms reinfected after the MDA produced a sufficient amount of eggs. Therefore, a more important factor may be the drug efficacy limitation of albendazole against $T$. trichiura.

Various workers have reported limited efficacy of albendazole and mebendazole for individual treatment of $T$. trichiura infection [1,6-9]. However, these drugs can be used in MDA because of considerable egg reduction rates, 77.0-99.0\% [6] or 39.0-60.6\% [7]. In particular, a long-term repeated use of albendazole or mebendazole at provincial or national level, up to 10 or more years (once or twice a year), markedly reduced the prevalence of T. trichiura in China $[11,12]$ and also in Cambodia (unpublished observations). In our study, egg reduction of $T$. trichiura was fairly remarkable after the MDA in Hlaingthar-yar district. These together indicate that a prolonged use of benzimidazoles must be beneficial for long-term control of T. trichiura.

However, it should be reminded that Moser et al. [1,7] demonstrated a considerable temporal decrease of benzimidazole efficacy against trichuriasis, possibly in part due to an emergence of drug resistance. For example, 73\% egg reduction rate of T. trichiura by albendazole in 1995 dropped down to $43 \%$ in 2015, and $91 \%$ egg reduction rate of T. trichiura by mebendazole in 1995 dropped down to 55\% in 2015 [1]. Cure rates of albendazole also fell from $38.6 \%$ in 1995 to $16.4 \%$ in 2015 [7]. These decreases in efficacy could be explained by study-related confounders or by anthelmintic drug resistance [1]. Further studies are required to identify single nucleotide polymorphisms in the parasite gene which is associated with the drug resistance [1].

Our study clearly demonstrated difficulty in short-term control of T. trichiura by MDA using $400 \mathrm{mg}$ single dose of albendazole and suggested the necessity of either a prolonged use of albendazole or use of an alternative regimen of albendazole or an alternative anthelmintic drug in the surveyed region of Myanmar. In this respect, sustained use of albendazole (400 mg single dose) for more than 10 years, or trial of new regi- mens of albendazole, for example, $400 \mathrm{mg}$ daily for 2-3 days, might be considered. However, the latter method seems not so feasible and not convenient for MDA, and repeated drug intake in each child may provoke untoward effects. Increasing the single dose of albendazole, for example, to $600 \mathrm{mg}$ revealed no better efficacy than the recommended dose (400 $\mathrm{mg}$ ) in treating T. trichiura infection [8].

Alternative drugs for T. trichiura include tribendimidine, ivermectin, oxantel pamoate, and moxidectin [1]. One or more of these drugs in combination with albendazole can be new candidates for use against T. trichiura [1,9]. In particular, oxantel pamoate alone or in combination with albendazole showed higher cure and egg reduction rates than albendazole alone [9]. However, oxantel pamoate is currently unavailable in Myanmar and will be expensive if imported from foreign countries. In the study of Speich et al. [9], oxantel pamoate and the matching placebo were self-manufactured at the University of Basel, Switzerland. Albendazole plus ivermectin, albendazole plus tribendimidine, and albendazole plus moxidectin can be other drug combinations for possible use in $T$. trichiura infection [1].

In our study, the egg positive rate of $O$. viverrini/MIF among the schoolchildren was very low, $<0.1 \%$ on average. It is comparable with our previous report from the same districts targeting village people who revealed $0.7 \%$ egg prevalence of $O$. viverrini/MIF among 2,057 subjects examined [13]. The only adult worm $(\mathrm{n}=1)$ harvested after chemotherapy and purging of an egg-positive villager was identified as O. viverrini [13]. Some Enterobius vermicularis eggs (among others; Table 1) were also detected from a few schoolchildren; however, this does not reflect the true figure of $E$. vermicularis infection because anal swab examinations should be done to properly evaluate the status of this nematode infection. It is worth to mention that our group separately performed anal swab examinations on a total of 761 schoolchildren in the same 3 districts of Yangon Region, and the average egg positive rate of $E$. vermicularis appeared to be very high, $47.2 \%$ [14].

Taken together, our study (MDA) using a single oral dose (400 mg) of albendazole showed a successful result for shortterm (4 months) control of A. lumbricoides in primary schools of 3 districts in Yangon Region. However, its efficacy was not satisfactory in short-term control of T. trichiura in the same districts. Either prolonged use of albendazole for more than 10 years or changing the albendazole regimen into 2-3-day course (total $800 \mathrm{mg}$ or 1,200 mg), or use of an alternative drug, for 
example, oxantel pamoate, may bring about better control efficacy against $T$. trichiura infection in this region.

\section{ACKNOWLEDGMENTS}

We are grateful to the teachers and staff of the subjected primary schools in South Dagon, North Dagon, and Hlaing-tharyar in Yangon Region, Myanmar for their assistance and guidance of the schoolchildren, collection of fecal samples, and MDA using albendazole.

\section{CONFLICT OF INTEREST}

The authors declare that they have no conflict of interest related to this study.

\section{REFERENCES}

1. Moser W, Schindler C, Keiser J. Drug combinations against soiltransmitted helminth infections. Adv Parasitol 2019; 103: 1-25.

2. Montresor A, Zin TT, Padmasiri E, Allen H, Savioli L. Soil-transmitted helminthiasis in Myanmar and approximate costs for countrywide control. Trop Med Int Health 2004; 9: 1012-1015.

3. Tun A, Myat SM, Babrielli AF, Montresor A. Control of soiltransmitted helminthiasis in Myanmar: results of 7 years of deworming. Trop Med Int Health 2013; 18: 1017-1020.

4. Htoon TT, Tun T, Oo KY, Thein W, Tin HH, Chai JY, Yong TS, Sohn WM. Status of infection with soil-transmitted helminths among primary school children in three selected townships of Yangon Region. Myanmar Health Sci Res J 2015; 27: 221-226.
5. World Health Organization. Prevention and Control of Intestinal Parasitic Infections: Report of a WHO Expert Committee. Geneva, Switzerland. World Health Organization. 1987, pp. 1-86.

6. Chai JY. Recent advances in the use of anthelmintics for treating nematode infections. Infect Chemother 2011; 43: 26-35 (in Korean).

7. Moser W, Schindler C, Keiser J. Efficacy of recommended drugs against soil transmitted helminths: systematic review and network meta-analysis. BMJ 2017; 358: j4307.

8. Chai JY, Hong ST. Chemotherapy of intestinal nematode infections. J Korean Soc Chemother 1985; 3: 119-129.

9. Speich B, Ame SM, Ali SM, Alles R, Huwyler J, Hattendorf J, Utzinger J, Albonico M, Keiser J. Oxantel pamoate-albendazole for Trichuris trichiura infection. N Engl J Med 2014; 370: 610-620.

10. Beaver PC, Jung RC, Cupp EW. Clinical Parasitology. 9th ed. Philadelphia, USA. Lea \& Febiger. 1984, pp 242.

11. Tian H, Luo J, Zhong B, Huang Y, Xie H, Liu L. Challenges in the control of soil-transmitted helminthiasis in Sichuan, Western China. Acta Trop 2019; 199: 105132.

12. Zeng XJ, Jiang WS, Xie SY, Chen YD, Gu XN, Ge J, Hang CQ, Li ZJ, Chen HG. Effect of integrated control intervention on soiltransmitted helminth infections in Jiangxi province in southeast China. Acta Trop 2019; 194: 148-154.

13. Sohn WM, Jung BK, Hong SJ, Lee KH, Park JB, Kim HS, Cho S, Htoon TT, Tin HH, Chai JY. Low-grade endemicity of opisthorchiasis, Yangon, Myanmar. Emerg Infect Dis 2019; 25: 14351437.

14. Chai JY, Yang SK, Kim JW, Choi SL, Song GY, Jung BK, Kim MJ, Cho J, Kim DG, Sohn WM, Jeoung HG, Cho S, Park JB, Hong S, Htton TT, Tin HH. High prevalence of Enterobius vermicularis infection among school children in three townships around Yangon, Myanmar. Korea J Parasitol 2015; 53: 771-775. 